\title{
Consuming Costly Prey: Optimal Foraging and the Role of Compensatory Growth
}

\author{
Randall Brian Langerhans ${ }^{1 *}$, Taylor R. Goins ${ }^{1}$, Kenzi M. Stemp ${ }^{2}$, Rüdiger Riesch ${ }^{3}$, \\ Márcio S. Araújo ${ }^{4}$ and Craig A. Layman ${ }^{5 t}$
}

${ }^{1}$ Department of Biological Sciences, W. M. Keck Center for Behavioral Biology, North Carolina State University, Raleigh, NC, United States, ${ }^{2}$ Department of Biology, Appalachian State University, Boone, NC, United States, ${ }^{3}$ Department of Biological Sciences, Centre for Ecology, Evolution and Behaviour, Royal Holloway, University of London, Egham, United Kingdom, ${ }^{4}$ Instituto de Biociências, Universidade Estadual Paulista (UNESP), Rio Claro, Brazil, ${ }^{5}$ Department of Applied Ecology, North Carolina State University, Raleigh, NC, United States

OPEN ACCESS

Edited by:

J. Jaime Zúñiga-Vega, National Autonomous University of Mexico, Mexico

Reviewed by: Regina Vega Trejo, Stockholm University, Sweden Geoff Smith, Denison University, United States

*Correspondence:

Randall Brian Langerhans langerhans@ncsu.edu

tPresent address: Craig A. Layman, Department of Biology, Center for

Energy, Environment, and Sustainability, Wake Forest University, Winston-Salem, NC, United States

Specialty section:

This article was submitted to Behavioral and Evolutionary Ecology,

a section of the journal

Frontiers in Ecology and Evolution

Received: 06 September 2020

Accepted: 14 December 2020

Published: 18 March 2021

Citation:

Langerhans RB, Goins TR Stemp KM, Riesch R, Araújo MS and Layman CA (2021) Consuming Costly

Prey: Optimal Foraging and the Role of Compensatory Growth.

Front. Ecol. Evol. 8:603387.

doi: 10.3389/fevo.2020.603387
Some prey are exceptionally difficult to digest, and yet even non-specialized animals may consume them - why? Durophagy, the consumption of hard-shelled prey, is thought to require special adaptations for crushing or digesting the hard shells to avoid the many potential costs of this prey type. But many animals lacking specializations nevertheless include hard-bodied prey in their diets. We describe several non-mutually exclusive adaptive mechanisms that could explain such a pattern, and point to optimal foraging and compensatory growth as potentially having widespread importance in explaining costly-prey consumption. We first conducted a literature survey to quantify the regularity with which non-specialized teleost fishes consume hard-shelled prey: stomach-content data from 325 teleost fish species spanning 82 families $(57,233$ stomach samples) demonstrated that non-specialized species comprise $\sim 75 \%$ of the total species exhibiting durophagy, commonly consuming hard-shelled prey at low to moderate levels ( $\sim 10-40 \%$ as much as specialists). We then performed a diet survey to assess the frequency of molluscivory across the native latitudinal range of a small livebearing fish, Gambusia holbrooki, lacking durophagy specializations. Molluscivory was regionally widespread, spanning their entire native latitudinal range ( $>14^{\circ}$ latitude). Third, we tested for a higher frequency of molluscivory under conditions of higher intraspecific resource competition in Bahamian mosquitofish (Gambusia spp.). Examining over 5,300 individuals, we found that molluscivory was more common in populations with higher population density, suggesting that food limitation is important in eliciting molluscivory. Finally, we experimentally tested in G. holbrooki whether molluscivory reduces growth rate and whether compensatory growth follows a period of molluscivory. We found that consumption of hard-shelled gastropods results in significantly reduced growth rate, but compensatory growth following prior snail consumption can quickly mitigate growth costs. Our results suggest that the widespread phenomenon of costlyprey consumption may be partially explained by its relative benefits when few alternative prey options exist, combined with compensatory growth that alleviates temporary costs.

Keywords: durophagy, food web, growth compensation, niche partitioning, predator-prey interactions, prey choice, resource competition, trophic ecology 


\section{INTRODUCTION}

Competition for food resources serves as one of the most important factors driving major ecological and evolutionary patterns (e.g., Tilman, 1982; Schluter, 2000; Chase and Leibold, 2003; Morin, 2011; Pfennig and Pfennig, 2012). This fact has led to an array of adaptations, where particular species have evolved different resource specializations for acquiring and consuming certain types of foods. For instance, animals have evolved specialized means of feeding on potentially costly prey, such as those characterized by toxins, thorns, spines, and hard shells (e.g., Savitzky, 1983; Benkman, 1993; Coley and Barone, 1996; Brodie, 1999; Wainwright, 2006). Nevertheless, many animals exhibit a broad diet, opportunistically feeding on a variety of organisms, and appear to regularly include the consumption of seemingly costly prey (Westoby, 1978; Rex et al., 2010).

Throughout, we refer to "costly prey" as those prey whose acquisition and consumption can cause reduced fitness relative to feeding on most other prey regularly available and consumed by a given species (e.g., decreased survival, fecundity, mating success, parental care). Reduction in fitness can result from impacts such as reduced growth, condition/health, egg/embryo development, and age/size at maturity. Natural selection should generally favor diets comprising more easily acquired and consumed prey having higher net energy intake, i.e., more beneficial cost-to-benefit ratios (MacArthur and Pianka, 1966; Schoener, 1971; Pyke et al., 1977; Pyke, 1984; Stephens and Krebs, 1986). But then what might explain the widespread consumption of costly prey?

We suggest four adaptive, non-mutually exclusive mechanisms might explain the phenomenon of eating costly prey items (Box 1). The four mechanisms represent two categories of explanation: (1) consumption of costly prey could reflect adaptive feeding strategies (mechanisms I-III), and (2) costs can potentially be offset through evolved mechanisms that provide a delayed compensation for the costs (mechanism IV). In this study, we seek to explain why so many animals consume prey items that not only seem relatively less profitable than other options, but seem particularly costly. That is, we are specifically concerned with the consumption of especially costly prey in nonspecialized taxa, and not merely the inclusion of poor-quality or low-cost prey in diets, or the very rare (perhaps inadvertent) consumption of moderate- to high-cost prey. We suggest that two particular mechanisms, optimal foraging, and compensatory growth, seem especially likely to prove important in explaining this phenomenon in nature, as the conditions conducive for their operation are common: decades of literature have revealed strong support for optimal foraging theory, and compensatory growth is widespread throughout the animal kingdom (see Box 1). In essence, costly-prey consumption may be largely explained by animals making the best of a bad situation (optimal foraging) and having the ability to offset its negative impacts by rapidly achieving a body size or condition associated with high fitness after the resumption of a high-quality diet (compensatory growth; Figure 1).

Here we test the predictions of optimal foraging and compensatory growth to evaluate their role in explaining durophagy in fishes. Durophagy describes the consumption of hard-shelled prey, including snails, bivalves, crabs, and urchins. This type of diet is typically thought to demand distinctive adaptations for crushing the hard shells, such as blunt teeth and strong jaws (Liem, 1986; Wainwright, 1988; Grubich, 2003; Hulsey et al., 2008). So why would animals lacking such specializations consume hard-bodied prey that will likely result in fitness costs? Durophagy can induce costs such as reduced growth of somatic or reproductive tissue owing to the large proportion of indigestible material consumed, spatial constraints within the gut as hard prey slowly evacuate (restricting entry, digestion, and evacuation of other prey, and potentially constraining available space for eggs or developing embryos), and possible injuries during consumption or excretion. Yet previous work on fish diets suggests that many fish lacking specializations might commonly include hard-shelled prey in their diet (see literature survey below). In this study, we (1) conduct a literature survey to quantify the regularity with which non-specialized teleost fishes consume hard-shelled prey, (2) perform a non-invasive diet survey to assess the frequency of molluscivory across the native latitudinal range of a wide-ranging, small, livebearing fish, Gambusia holbrooki, (3) test optimal foraging predictions of higher frequency of molluscivory under conditions of higher intraspecific resource competition in Bahamian mosquitofish (Gambusia spp.), and (4) conduct an experimental test in $G$. holbrooki for a cost of molluscivory (i.e., reduced growth rate) and the occurrence of compensatory growth following a period of molluscivory.

\section{MATERIALS AND METHODS Literature Survey of Durophagy in Teleost Fishes}

To estimate the occurrence of hard-shelled prey in the diet of wild teleost fishes, we conducted a literature search of diet studies that employed stomach-content analysis. Rather than attempt to provide an exhaustive review of fish diets, we limited our search to the first 100 studies we encountered that matched the criteria described below. In this way, our search should provide a representative sample of fish diets, approximating what an exhaustive literature review might find. Using Google Scholar, we searched for studies of fish diets that directly examined stomach contents of wild-caught teleost fish, and provided quantitative information relevant to determining the inclusion of hard-shelled prey in the diets. Quantitative diet information was gathered for five different estimates of hard-shelled prey consumption: (1) percent occurrence (number of stomachs with hard-shelled prey / total number of stomachs that contained prey items), (2) percent by number (number of hard-shelled prey items / total number of prey items), (3) percent by weight (weight of hardshelled prey / weight of all prey), (4) percent by volume (volume of hard-shelled prey / volume of all prey), and (5) percent index of relative importance. This latter metric is a commonly employed compound index of fish diets, and incorporates occurrence, bulk, and amount: percent occurrence $\times$ (percent volume + percent by number), expressed as a percentage of the sum of all index of relative importance values for all prey items [for details, see Pinkas et al. (1971), Cortes (1997)]. This large set of studies 


\section{BOX 1 | Why animals consume costly prey}

We describe and evaluate four adaptive explanations for the consumption of costly diet items in non-specialized animals (Table I).

TABLE I | Four adaptive, non-mutually exclusive mechanisms to explain the consumption of costly prey in non-specialized taxa.

\begin{tabular}{|c|c|}
\hline Mechanism & Description \\
\hline I. Direct benefits & $\begin{array}{l}\text { Costly prey provide direct advantages that result in net fitness benefit, such as essential limiting nutrients or buffer effects of toxic } \\
\text { compounds. }\end{array}$ \\
\hline II. Individual specialization & Some individuals possess specialized traits that reduce the costs of costly prey. \\
\hline III. Optimal foraging & Costly prey are relatively less costly than alternative prey or no prey at all. \\
\hline IV. Compensatory growth & $\begin{array}{l}\text { Mitigate negative effects of costly-prey consumption by later exhibiting accelerated growth of somatic or reproductive tissue following } \\
\text { consumption of higher-quality resources. }\end{array}$ \\
\hline
\end{tabular}

Mechanism I-Direct benefits: Animals could attain a net fitness gain from consuming particularly difficult-to-eat prey because they confer important benefits. Despite substantial costs, certain prey might provide important limiting nutrients, aid in detoxifying compounds derived from other foods, support mechanical digestion, or facilitate the removal of obstructions, parasites, or harmful microbiota (Bernays et al., 1994; Provenza et al., 2003; Simpson et al., 2004; Voigt et al., 2008). While consumption of some inedible items, such as clay or soil, might offer some important benefits at low to moderate cost, this "direct benefits" mechanism seems unlikely to commonly explain the consumption of prey that induce considerable costs, as the gains would need to be quite large to overcome the costs-unless the costly prey was only infrequently consumed in small amounts. Thus, although theoretically possible, and potentially important in combination with other mechanisms, we doubt that this mechanism alone can explain frequent or moderate levels of consumption of particularly costly prey.

Mechanism II-Individual specialization: Competition for food can drive intraspecific resource partitioning to reduce the intensity of competition, where individuals within a population differ in their ranked preferences of prey items. That is, some individuals rank costly prey items higher than others due to frequency-dependent competition (Bolnick, 2001) and specialized phenotypes that reduce costs of acquiring and consuming those prey resources (Bolnick et al., 2003). For instance, individuals might possess certain behaviors, morphologies, or physiologies that enhance foraging or feeding performance for costly prey, and thus more readily consume those prey than other individuals less equipped to contend with these resources (Olsson et al., 2007). This scenario results in individual diet specialization (e.g., Bolnick et al., 2003; Svanbäck and Persson, 2004; Svanbäck and Bolnick, 2007; Araujo et al., 2011), with certain individuals consistently feeding on costly prey more frequently than other individuals. Certain cases of intraspecific resource polymorphisms provide one source of known examples of this scenario, where phenotypically-specialized subsets of populations consume costly prey items, such as snail-feeding within several cichlid fishes and hard-seed consumption within some finches (e.g., Smith and Skúlason, 1996; Swanson et al., 2003). However, for individual specialization to account for the widespread consumption of costly prey in "non-specialized" species, there must be considerable cryptic phenotypic variation within populations that has so far gone undetected. While the occurrence of individual diet specialization appears pervasive across many taxa (e.g., Bolnick et al., 2003; Araujo et al., 2011), whether or not such specialization often comprises specialized phenotypes that reduce the impact of costly-prey consumption is currently unknown.

Mechanism III-Optimal foraging: Animals might adaptively consume costly prey when the net energetic gain associated with that particular prey type is greater (or when the net energetic loss is smaller) than alternative prey options. This comprises a fundamental prediction of optimal foraging theory (e.g., Stephens and Krebs, 1986), where animals should increase consumption of suboptimal prey as higher-quality resources become more difficult to acquire. Specifically, if individuals rank prey resources largely based on net energy intake, and include different resources in their diet according to this criterion, then situations can arise where consumption of costly prey represents an adaptive foraging behavior because these prey become relatively less costly in comparison with other available prey. For instance, this might occur in cases of reduced abundance or absence of higher-quality resources, reduced access to higher-quality resources (e.g., interference competition, predation), increased abundance of costly prey, or increased encounter rates with costly prey within less risky foraging areas. This might be most prevalent during particular seasons, times of drought, in the face of strong resource competition, when particular individuals or species guard high-quality resources, or when elevated predation risk confines individuals to regions without higher-quality resources. Put simply, this mechanism provides a means by which animals can make the best of a bad foraging situation. This mechanism could prove common for suboptimal prey resources of moderate costliness, while particularly severe conditions might be required for this mechanism to wholly explain moderate levels of consumption of highly costly prey. Thus, the importance of this mechanism depends on the balance between the costliness of the prey and the severity of the alternative option of not eating the costly prey (e.g., starving, eating lower-quality resources, suffering a high risk of injury or death in attempting to acquire higher-quality resource).

Mechanism IV-Compensatory growth: Animals might endure temporary costs of consuming difficult-to-eat items, but exhibit compensatory growth that offsets these costs once they subsequently obtain higher-quality food. Compensatory growth describes a phase of accelerated growth when high-quality nutrition is restored after a period of growth depression (Osborne and Mendel, 1916; Bohman, 1955; Hornick et al., 2000), and is widespread in animals after diet/nutrient restriction and in plants following herbivory (Wilson and Osbourn, 1960; Tanner, 1963; McNaughton, 1983; Ryan, 1990; Ali et al., 2003; Hector and Nakagawa, 2012; Won and Borski, 2013). Because body size often has a strong link to fitness (Roff, 2002), compensatory growth has been thought to represent an adaptation to avoid negative consequences of reduced body size caused by episodes of reduced growth. Thus, animals might more readily accept costs of suboptimal prey consumption partially because elevated growth later will compensate for these costs, resulting in little to no net reduction in fitness. Natural selection might often favor such a strategy in systems that meet two criteria: (1) temporally or spatially patchy distributions of high-quality food resources, occasionally requiring consumption of costly prey (e.g., via mechanism III), and (2) high likelihood of acquiring higher-quality food within a relatively short period after costly-prey consumption. The latter criterion implies a low mortality risk during the compensatory growth phase, as an individual cannot offset fitness costs at a later date if it cannot survive until that time. These two criteria are often met in natural populations, and combined with both the pervasiveness of compensatory growth and the ability of compensatory growth to minimize fitness costs, this mechanism might play an important, previously unrecognized role in explaining the common phenomenon of costly-prey consumption in natural animal populations. Whether animals initially consume costly prey because of direct benefits, to reduce intraspecific competition via individual specialization, or through optimal foraging strategies, compensatory growth might provide a common solution for offsetting costs. That is, complete elimination of costs is unlikely through any of the three mechanisms described above, and thus selection should often favor an additional mechanism that can largely offset those costs. Based on our current knowledge, compensatory growth seems to hold considerable promise as a widespread, influential factor in permitting costly-prey consumption. 


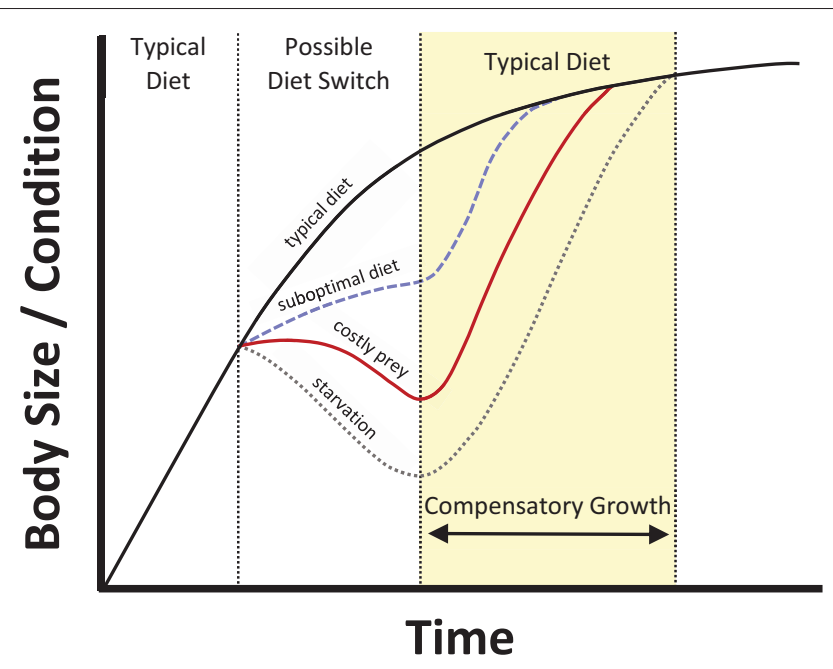

FIGURE 1 | Illustration of possible negative consequences of costly-prey consumption, and the rapid offsetting of costs via compensatory growth. Costly-prey consumption might often entail strong fitness costs relative to other prey items (especially in the absence of mechanisms I or II, Box 1), but still offer more energetic return than starvation, with compensatory growth providing a generalized response to counteract periods of growth depression.

should provide reasonable estimates of our parameters of interest (see Results for species diversity and sample size). All studies included in this review, and their associated data, are presented in Appendix 1 in the Supplementary Material.

To avoid ambiguities and maintain consistency across studies, we only included molluscs and crabs in our category of "hardshelled prey" even though some other prey may have shells or other dense parts (e.g., ostracods). For mollusc prey, unequivocal quantitative data for hard-shelled molluscs must have been provided in the study for inclusion in our dataset. For some studies, we could not obtain estimates of hard-shelled prey consumption even though quantitative data were provided; we excluded those studies. For instance, we excluded studies that only provided percent occurrence data separately for different mollusc species because this did not allow us to determine the overall percent occurrence of all molluscs (i.e., stomachs could have contained multiple mollusc species). Inclusion of crab prey data followed the same criteria, with the exception that if a study only provided values for the entire group of "crustaceans" or "decapods," we ignored those values and assumed the groups did not contain crabs. This conservative approach likely biased our estimates downward only slightly, as this only occurred in three studies, and in all these cases it was unlikely that crabs comprised a substantial part of the diet owing to the habitat use and diet of these species.

We classified each fish species included in the dataset as either a "specialist" or "non-specialist" based on the presence or absence of specialized morphological features for crushing and consuming hard-shelled prey. This classification was straightforward and unambiguous in all cases, as species with durophagous specializations are well-known. Typically, durophagous specialists possess specialized pharyngeal jaw morphologies accompanied by large, strong epaxial muscles (e.g., Liem, 1986; Wainwright, 1988; Meyer, 1990; Grubich, 2003; Hulsey et al., 2008). We further classified each species as either exhibiting durophagy or not, based on the presence or absence of hard-shelled prey in their diet. Because durophagy can be rare in non-specialists, low sample sizes might fail to detect durophagy within populations where it is present at low frequency. To test whether the detection of durophagy depended on sample size in our dataset, we conducted logistic regression for nonspecialists with the presence of durophagy as the dependent variable (0 vs. 1 ) and $\log _{10}$-transformed sample size (number of stomachs examined) as the independent variable. We did not include specialists in this test because durophagy was detected in all specialists, regardless of sample size (see below). If sample size affected the detection of durophagy, then we would exclude species with low sample sizes (either $<5$ or 10 individuals, using separate analyses) where durophagy was not detected, and reperform the logistic regression to determine whether the samplesize dependence of durophagy detection could be eliminated by excluding species with particularly small sample sizes. If so, then we would exclude those species with small sample sizes for all analyses. All analyses in this study were performed in the programs SAS v.7.15 and JMP v. 14.2 (SAS Institute Inc., Cary, NC, USA).

\section{Field Survey of Molluscivory in Gambusia holbrooki}

Gambusia fishes are small, livebearing fish (family Poeciliidae) that exhibit wide-ranging diets (Meffe and Snelson, 1989; Pyke, 2005), occasionally consuming hard-shelled molluscs by swallowing them whole (Bay and Anderson, 1966; Hubbs et al., 1978; Walters and Legner, 1980; Hubbs, 1990; Pen and Potter, 1991; Araujo et al., 2014). We selected G. holbrooki for detailed investigation because of its broad diet, extensive geographic range, lack of any adaptive specializations for durophagy, potential for substantial costs of molluscivory in terms of both growth and reproduction, and ability to exhibit compensatory growth (Kahn et al., 2012; Livingston et al., 2014).

We collected G. holbrooki in August 2011 from 10 natural populations along the eastern coast of the United States, spanning their entire native latitudinal range (Figure 2A, Supplementary Table 1). Specimens were immediately euthanized and preserved in 95\% ethanol upon collection. We used digital x-ray imaging to examine the presence/absence of molluscs in gut contents of preserved adult G. holbrooki (261 females, 170 males). We captured a digital x-ray of each fish in the lateral perspective using a custom-built digital $\mathrm{x}$-ray unit comprising a micro-focus $\mathrm{x}$-ray source (Hamamatsu L6731-01) and a digital x-ray detector (PaxScan 2520E) housed in a lead-shielded cabinet. We inspected each image for the occurrence (presence/absence) and number of molluscs within the stomach. Previous work demonstrated the feasibility of this technique for detection of hard-shelled prey, such as molluscs (Beckmann et al., 2015). Because direct stomach-content analysis of a subset of fish revealed that snails smaller than $1 \mathrm{~mm}$ shell 

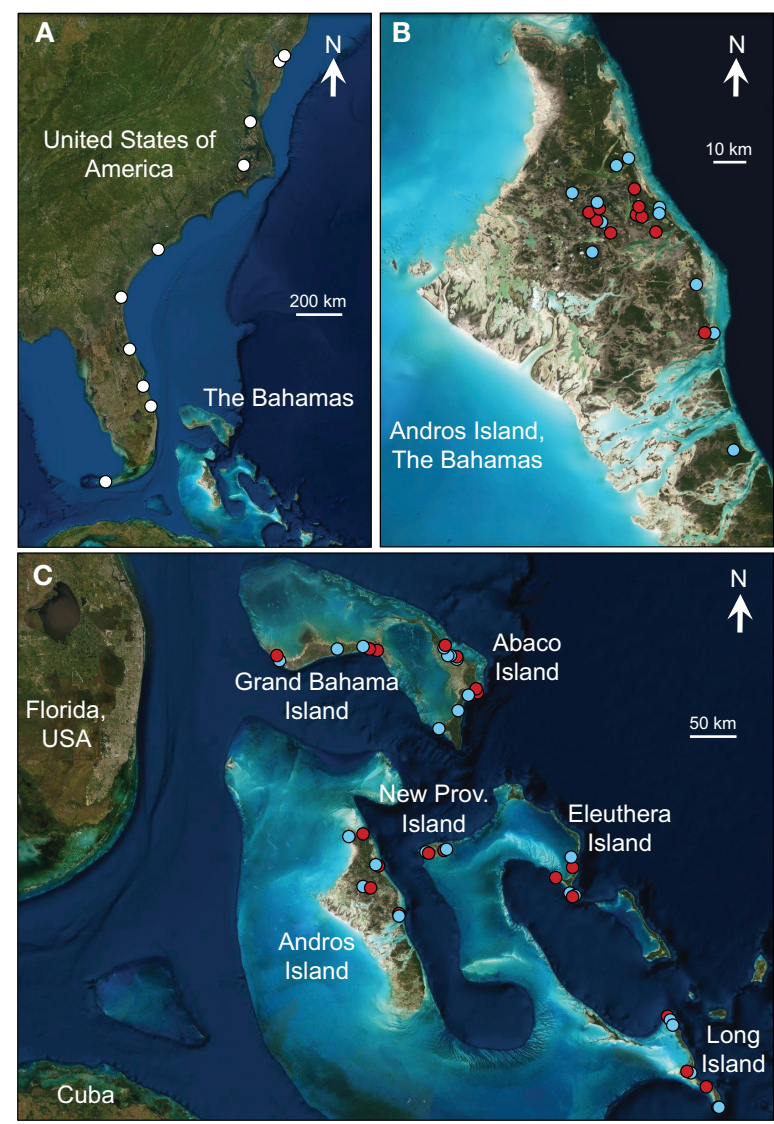

FIGURE 2 | Map of collection localities for the field studies of molluscivory in (A) Gambusia holbrooki, (B) G. hubbsi in blue holes, and (C) three species of Bahamian mosquitofish in tidal creeks. Blue symbols: high density/low predation; red symbols: low density/high predation.

length were rarely detected by $\mathrm{x}$-ray imaging, our estimates provide lower bounds for the frequency of molluscivory in $G$. holbrooki, capturing cases of particularly dense mollusc shells (see Figure 3). Moreover, because $\mathrm{x}$-ray imaging could not unequivocally determine which stomachs were empty and which contained prey items (Beckmann et al., 2015), our estimate of percent occurrence of molluscivory was calculated as the number of fish with snails in their stomachs divided by the total number of fish examined (rather than the total number of fish with prey items in their stomach).

\section{Molluscivory and Resource Competition in Bahamian Mosquitofish}

To test whether increased levels of resource competition are associated with molluscivory, as predicted by optimal foraging theory, we examined endemic livebearing fish in The Bahama Archipelago. Bahamian Gambusia were selected for study for reasons similar to G. holbrooki, with the added feature that they inhabit environments known to vary substantially in population density, with prior work finding multiple lines of evidence indicating stronger resource competition in populations with

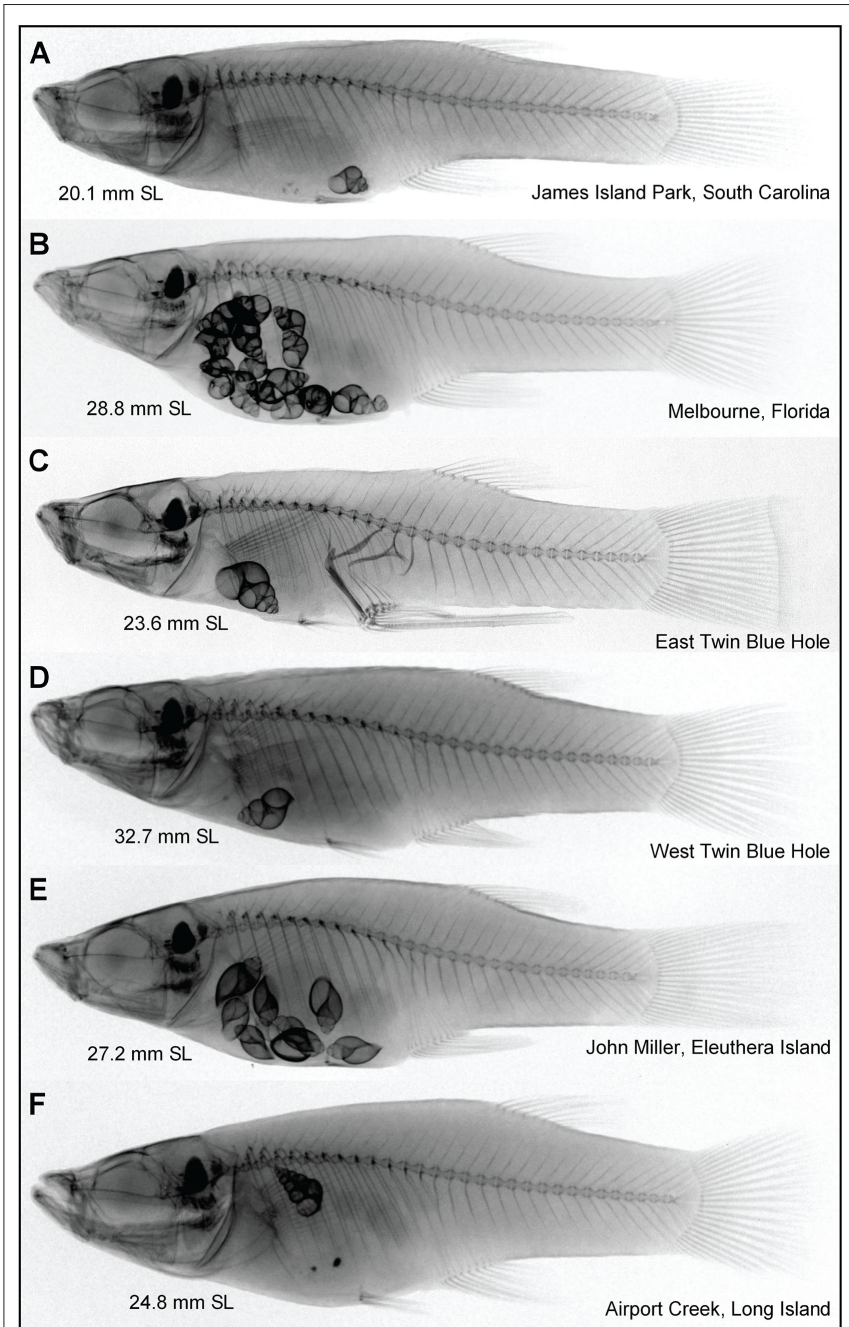

FIGURE 3 | Representative X-ray images of wild-caught (A,B) Gambusia holbrooki, (C,D) Gambusia hubbsi, and (E,F) Gambusia manni that had consumed snails (standard length of each fish provided).

higher densities (Heinen et al., 2013; Riesch et al., 2013, 2015; Araujo et al., 2014; Heinen-Kay et al., 2016; Langerhans, 2018). We conducted our tests in two separate systems: (1) Gambusia hubbsi in inland blue holes on Andros Island and (2) three Gambusia species in tidal creeks across six islands. In all cases, we immediately euthanized and preserved individuals in $95 \%$ ethanol upon collection.

During the past $\sim 15,000$ years (Fairbanks, 1989), G. hubbsi colonized many inland blue holes (water-filled, vertical caves) and have subsequently undergone adaptive diversification in a large number of traits [reviewed in Langerhans (2018)] and evolved varying levels of reproductive isolation among populations (e.g., Langerhans et al., 2007; Langerhans and Makowicz, 2013). A primary driver of evolutionary divergence in this system stems from the fact that in some blue holes $G$. hubbsi experience a relatively predator-free environment devoid of any piscivorous fish, and consequently exhibit high population 
densities with elevated competition for food resources. In other blue holes, G. hubbsi are heavily preyed upon by the much larger bigmouth sleeper (Gobiomorus dormitor) and have much lower population densities (e.g., Langerhans et al., 2007; Heinen et al., 2013; Martin et al., 2015). Because these two categories of blue holes do not systematically differ in abiotic environmental variables (Langerhans et al., 2007; Heinen et al., 2013; Riesch et al., 2013; Björnerås et al., 2020), this system provides a remarkable opportunity to test for the role of altered predatory and competitive environment on diet.

For G. hubbsi inhabiting blue holes on Andros Island, we tested for increased frequency of molluscivory under scenarios of higher resource competition by examining $\mathrm{x}$-ray radiographs of 2,248 adult fish collected from 21 populations (11 with high density and no predators, 10 with low density and predatory fish present; Figure 2B, Supplementary Table 2). For each site, we calculated the overall proportion of fish with molluscs in their guts. For statistical analysis, we conducted a one-way analysis of variance (ANOVA) using arc-sin squareroot transformed proportional molluscivory as the dependent variable and the dichotomous factor "predation regime" (highdensity/low-predation vs. low-density/high-predation) as the independent variable.

Bahamian tidal creeks are shallow, tidally influenced estuaries typically having a relatively narrow creek mouth that broadens landward. Water flux largely arises from tidal exchange (freshwater input only provided via rainfall and aquifer percolation), so salinities in unfragmented systems are typically around 35 ppt and the biotic communities comprise marine taxa (Layman et al., 2004; Valentine-Rose et al., 2007a,b; Araujo et al., 2014; Riesch et al., 2015). Three species of Bahamian mosquitofish (G. hubbsi, G. manni, and G. sp.) inhabit tidal creeks across the archipelago, with each species within these systems found on different islands (Heinen-Kay et al., 2014). Fragmentation of Bahamian tidal creeks-the process by which connectivity with the ocean is restricted or cut off entirely-is principally caused by road construction, and results in strong and persistent ecological change. Most road construction that fragmented tidal creeks occurred during the 1960s and 1970s. Fragmentation dramatically reduced tidal exchange (tidal amplitude $\sim 0-10$ vs. $\sim 40-80 \mathrm{~cm}$ in unfragmented creeks), leading to increased sedimentation rates, reduced animal biomass, reduced species diversity, and changes in the community composition of fishes, macroinvertebrates, plants, and macroalgae (Layman et al., 2004; Valentine-Rose et al., 2007a,b, 2011; Valentine-Rose and Layman, 2011; Araujo et al., 2014; Riesch et al., 2015). Key among these changes are markedly reduced densities of piscivorous fishes (e.g., great barracuda, Sphyraena barracuda; needlefish, Strongylura spp.) and increased densities of Bahamian mosquitofish. Previous work suggests that these drastic changes in intraspecific resource competition and predation represent the drivers of rapid phenotypic change in Bahamian mosquitofish in these systems (Araujo et al., 2014; Heinen-Kay et al., 2014; Giery et al., 2015; Riesch et al., 2015).

We employed two methodological approaches to test for consistent differences in molluscivory of Bahamian mosquitofish between the high-competition conditions of fragmented tidal creeks and the low-competition scenarios of unfragmented tidal creeks. First, we used x-ray radiographs of 2,463 adults from 44 populations across six Bahamian islands (two islands for each of three species; 1,466 females, 997 males; Figure 2C, Supplementary Table 3) to measure the proportion of fish with molluscs in their guts at each site. Again, the limitations of this method mean that our estimates provide a lower bound, likely underestimating the frequency of molluscivory because small molluscs ( $<1 \mathrm{~mm}$ shell length) can go undetected and because all fish, not only those with prey items in their stomachs, were used as the denominator in the percent occurrence calculation. We conducted a general linear model with arc-sin square-roottransformed proportional molluscivory as the dependent variable to test for effects of fragmentation regime, species, the interaction between species and fragmentation regime, island nested within species, and the interaction between fragmentation and island nested within species. Second, we complemented this noninvasive method with direct examination of stomachs because this could reveal smaller, less dense snail, and bivalve shells than detectable with $\mathrm{x}$-rays. For this reason, and to additionally examine individuals particularly vulnerable to costly growth reductions caused by molluscivory, we included juveniles in our stomach-content analyses. We examined stomachs of 625 G. sp. on Abaco Island (373 females, 122 males, 130 juveniles) from 13 tidal creeks that span wide, continuous variation in population density (Supplementary Table 4). Some of these fish (156 females) were previously examined in Araujo et al. (2014), which can be consulted for details, but overall mollusc consumption has never previously been examined for these fish. Briefly, we removed the stomach of each individual in the laboratory and analyzed the gut contents under a stereo microscope, counting and identifying all prey items to the lowest feasible taxonomic level. To estimate the frequency of molluscivory, we calculated the average proportion of molluscs in the stomachs of each sex-age class for each population (number of molluscs divided by total number of prey items present in each stomach). We tested for greater molluscivory in populations with higher densities using an analysis of covariance (ANCOVA) with arc-sin square-root transformed proportion of molluscs as the dependent variable, and sex-age class and $\log _{10}$-transformed density as independent variables (interaction between sex-age class and $\log _{10}$-transformed density was excluded due to nonsignificance, $P=0.93$ ).

\section{Experimental Test of Cost of Molluscivory and Compensatory Growth in G. holbrooki}

We experimentally tested whether molluscivory induces a cost in terms of growth in G. holbrooki and whether these fish can exhibit compensatory growth after snail consumption to reduce costs. Because our field survey found that females consumed snails more frequently than males (see Results), and because males exhibit minimal growth after sexual maturity in G. holbrooki (reducing our ability to detect growth-rate changes), we only examined adult females in this experiment. We collected adult fish from a single population in Cary, North Carolina. We 
first confirmed the presence of molluscivory in this population through fecal examination of live fish (i.e., expelled whole shells), and verified willingness to consume molluscs for all fish before experimentation by feeding live Physa acuta snails to the fish. All fish were maintained in the lab several months prior to experimentation. Although pregnancy status varied among fish used in the experiment (15 of 24 fish were determined to be pregnant by examination after the experiment), none of the fish gave birth during the experiment, and pregnancy status was highly non-significant when included as a covariate in analyses described below (main effect and all interaction terms: $P>0.65$ ). Thus, we did not include pregnancy status in our final analyses.

We conducted a 17-day feeding experiment examining 24 female G. holbrooki [32.5-47.0 mm standard length (SL)]. The experiment was conducted in two temporal blocks, where we applied all the same experimental procedures twice, separated by 6 months (194 days), with 12 females examined within each block. For each block, each fish was individually placed in a 4.5$\mathrm{L}$ container with an aerator on day 1 , starved for $48 \mathrm{~h}$, and then received a single feeding of a prescribed treatment per day until day 17. We housed tanks side-by-side on two shelves within a single room, and assigned a feeding treatment, hard-bodied prey vs. soft-bodied prey, alternately to each tank to avoid any potential confounding of treatment with spatial location or shelf effects. Fish in the hard-bodied prey treatment were fed two $P$. acuta snails with shells intact per day for 8 days (days 3-10), and then received Tetra-min Pro flakes for 6 days (days 11-16). Fish in the soft-bodied prey treatment were fed two P. acuta snail bodies removed from their shells per day for 8 days (days 310), and then received a similar 6 days of Tetra-min Pro flakes (days 11-16). Thus, the only difference between prey treatments involved the inclusion/exclusion of the shell along with the snail body during the snail-feeding period of the experiment-i.e., nutritional value remained constant across treatments, assuming no nutritive content of the hard shell itself for Gambusia fishes. We weighed $(\mathrm{g})$ and measured standard length $(\mathrm{mm})$ of each fish on four occasions: days 3, 7, 11, and 17. Fish of relatively similar size were selected for experimentation, and body size did not differ between treatments ( $t$-test, initial mass: $P=0.58$; initial SL: $P=0.79$ ), nor did the average amount of snail mass fed to fish $(P=0.82)$. Fish mass changed considerably during the experiment, but length did not. Thus, we used initial SL as a potential covariate when examining variation in growth rate (g/day) during the experiment. To confirm low measurement error in our estimates of body size, we weighed and measured six similarly sized adult female G. holbrooki three times each and calculated repeatability as the intraclass correlation coefficient. Even though overall variation in body size was not high in this test (coefficient of variation $=0.14$ and 0.07 for mass and SL, respectively), we found that repeatability was extremely high in both cases (mass: $r>0.999$, SL: $r>0.998$ ), supporting our use of these estimates of body size.

We collected all $P$. acuta snails from the same locality as the G. holbrooki used in the experiment, and prepared snails for feeding in advance of the experiment by weighing and freezing each individual (thawed immediately prior to feeding). We assigned each snail to be fed to a particular fish in a manner that maintained consistency throughout the experiment in the average mass of snails fed per day to a given fish. We prepared the Tetra-min Pro flakes in advance by weighing the flakes to ensure that each fish received flakes weighing twice the average mass of snails fed to each particular fish. During the experiment, tanks were vacuumed of debris and fecal waste every other day. Tanks were checked periodically throughout each day to note any feces or passed snail shells, which were removed once sighted.

We calculated the average daily growth rate (g/day) of each fish during both feeding periods (snail-feeding and flake-feeding periods) using the mass data collected during the experiment and conducted a repeated-measures general linear mixed model to test for effects on growth rate for the following terms: feeding period (snails vs. flakes), prey treatment (hard vs. soft), the interaction between feeding period and prey treatment, fish SL, and snail mass (average daily snail mass fed to each fish). The latter two variables were included as covariates to control for potential effects of body size or the amount of prey consumed on growth rate. We also initially included all two-way interactions between main effects and covariates and excluded all highly non-significant interaction terms $(P$ $>0.4$ ) from our final model. We included individual and block as random effects. We were especially interested in the interaction between feeding period and prey treatment, as we hypothesized that fish in the hard-bodied prey treatment would suffer reduced growth rate during the snail-feeding period, but subsequently exhibit elevated (compensatory) growth during the flake-feeding period.

To visualize changes in mass throughout the experiment, we plotted the relative mass of G. holbrooki over time (the 17 days of the experiment, with four measurement periods), and used cubic regression to summarize growth trajectories within each treatment. We estimated relative mass as back-transformed residuals of a linear regression of mass on SL (residuals + mean), which resulted in values of mass for each fish for each measurement period, controlling for body length, in $g$ units. To provide an intuitive metric of recovery in the hard-prey treatment, we calculated the "compensatory index" following Wilson and Osbourn (1960). This index expresses the magnitude of compensatory mass gain as a percentage of the maximal mass differential between treatments, with a value of $100 \%$ indicating full recovery. We calculated the compensatory index as the difference in mass between treatments at the end of the snailfeeding period minus the difference in mass between treatments at the end of the flake-feeding period, divided by the mass difference at the end of the snail-feeding period.

\section{RESULTS}

\section{Literature Survey of Durophagy in Teleost Fishes}

We accumulated a dataset of 366 teleost fish species from 23 orders and 84 families, comprising stomach-content data from a total of 57,511 individual fish (Supplementary Appendix 1). Fifty one species from 18 families within this dataset were "durophage specialists," possessing adaptive morphological 
modifications for crushing and consuming hard-shelled preyall of these species exhibited durophagy in our dataset. Within non-specialists, we detected a strong, positive effect of sample size on the detection of durophagy $\left(\chi^{2}=19.32, P<0.0001\right)$. Thus, the detectability of durophagy within non-specialists depended on the sample size of stomachs examined. Excluding species with $<5$ stomach samples did not eliminate this sample-size dependency $\left(\chi^{2}=7.08, P=0.0078\right)$, but excluding species with $<10$ stomach samples $\operatorname{did}\left(\chi^{2}=1.20, P=0.2731\right)$. This resulted in a reduced dataset of 325 species from 22 orders and 82 families, comprising 57,233 stomach samples $(48,579$ for non-specialists, 8,654 for specialists). The reduced dataset did not remove any study completely from the analysis, as all excluded species derived from three studies that reported diets for multiple species, including some with large sample sizes (Randall, 1967; Winemiller and Ponwith, 1998; Lopez-Peralta and Arcila, 2002). We used this reduced dataset for all results presented here.

We found that over $63 \%$ of the species in our dataset exhibited durophagy (206 of 325 species). These 206 species spanned 14 orders (63.6\%) and 60 families (73.2\%). The majority of fish species that included hard-shelled prey in their diet did not possess specialized features for processing these prey: nonspecialists represented $\sim 75 \%$ of the species (155 of 206 species). Despite potential costs for consuming hard-shelled prey, nonspecialists typically consumed $10-40 \%$ as much hard-shelled prey as specialists, depending on the estimate of durophagy (Table 1). Even for specialized fishes, hard-shelled prey tended to comprise less than half of the diet on average (Table 1), consistent with broadly opportunistic foraging in most fishes, with partial reliance on specialized prey.

\section{Field Survey of Molluscivory in G. holbrooki}

We observed molluscivory in 8 of the $10 \mathrm{G}$. holbrooki populations examined, spanning their entire latitudinal range (Supplementary Table 1). While molluscivory appears widespread in G. holbrooki at the regional scale (especially in females), it was always locally uncommon within populations (3.3-13.3\% occurrence; based on all fish examined, not only those with prey items present), at least based on x-ray images, which likely failed to detect consumption of small molluscs $(<1 \mathrm{~mm})$. Overall, we detected molluscs in the stomachs of 13 of 261 females $(5.0 \%)$ and 2 of 170 males (1.2\%). For fish with mollusc shells apparent within their stomachs in $\mathrm{x}$-ray images, we found 1-20 shells present within a single stomach (Figures 3A,B), with a total of 56 shells observed. Individuals with molluscs in their stomach spanned a range of body size $(18.2-33.8 \mathrm{~mm} \mathrm{SL}$, mean $=26.5 \mathrm{~mm} \mathrm{SL})$, suggesting that adults of any body size might consume molluscs in the wild. All shells appeared to be gastropods (primarily Physa spp.), except for two bivalves.

\section{Molluscivory and Resource Competition in Bahamian Mosquitofish}

In blue holes on Andros Island, we detected molluscivory in G. hubbsi within all 11 blue holes having high population density and no predatory fishes, but detected molluscivory in only 4 of 10 blue holes with low population density and predatory fish present (Supplementary Table 2). Overall, we found a much higher frequency of molluscivory in highdensity/low-predation blue holes compared to low-density/highpredation blue holes $\left(F_{1,19}=14.48, P=0.0012\right.$; Figure 4A), consistent with the prediction from optimal foraging theory for a higher frequency of costly-prey consumption in populations experiencing stronger resource competition. Our lower-bound estimate of molluscivory indicated that it was generally rare, with an average of $3 \%$ of fish examined having molluscs in their guts for populations where molluscivory was detected. When molluscs were observed, between 1 and 18 shells were present within stomachs (Figures 3C,D). Again, individuals with molluscs in their stomach spanned a large range of body size $(17.0-49.2 \mathrm{~mm} \mathrm{SL}$, mean $=28.4 \mathrm{~mm} \mathrm{SL})$.

In Bahamian tidal creeks across six islands, we detected molluscivory using $\mathrm{x}$-ray radiographs in 18 of 44 populations (41\%), 47 of 1,466 females (3.2\%), and 7 of 997 males $(0.7 \%)$ (Supplementary Table 3). Consistent with the prediction from optimal foraging theory, we observed a higher frequency of molluscivory in the high-density scenarios of fragmented tidal creeks compared to unfragmented tidal creeks $\left(F_{1,32}=6.80\right.$, $P=0.0137$; Figure 4B). We found no differences between the three species in molluscivory $\left(F_{2,32}=0.42, P=0.66\right)$, nor any effects of the interaction between species and fragmentation status $\left(F_{2,32}=1.41, P=0.26\right)$. Similarly, we found no significant variation among islands within species $\left(F_{3,32}=0.96, P=0.42\right)$ or for the interaction between fragmentation status and island $\left(F_{3,32}=1.28, P=0.30\right)$. Fish with mollusc shells in their guts again spanned the full range of adult body size $(14.1-36.9 \mathrm{~mm}$ $\mathrm{SL}$, mean $=22.4 \mathrm{~mm} \mathrm{SL}$ ), and had between 1 and 10 shells within their stomachs (Figures 3E,F).

Using direct examination of stomach contents for Bahamian mosquitofish in 13 tidal creeks on Abaco Island, we found a much higher frequency of molluscivory than when using $\mathrm{x}$ ray methodology. Our observations indicated that this derived from smaller molluscs being detected using direct stomachcontent analysis. In all, we detected molluscivory in 12 of the 13 populations, with an average percent by number of

TABLE 1 | Summary of average quantitative diet information for the 206 fish species exhibiting durophagy within our dataset derived from our literature survey.

\begin{tabular}{|c|c|c|c|c|c|c|c|}
\hline $\begin{array}{l}\text { Durophage } \\
\text { specialization }\end{array}$ & $N$ & $\% 0$ & $\% \mathbf{N}$ & $\% \mathbf{W}$ & $\% \mathbf{V}$ & \% IRI & Stomachs \\
\hline Non-specialized & 155 & 7.68 & 8.64 & 12.61 & 19.99 & 4.53 & 34,273 \\
\hline Specialized & 51 & 39.83 & 28.07 & 42.14 & 43.67 & 39.96 & 8,654 \\
\hline
\end{tabular}

$\%$ O, percent occurrence; $\% \mathrm{~N}$, percent by number; $\% \mathrm{~W}$, percent by weight; $\% \mathrm{~V}$, percent by volume; \% IRI, percent index of relative importance. 
A

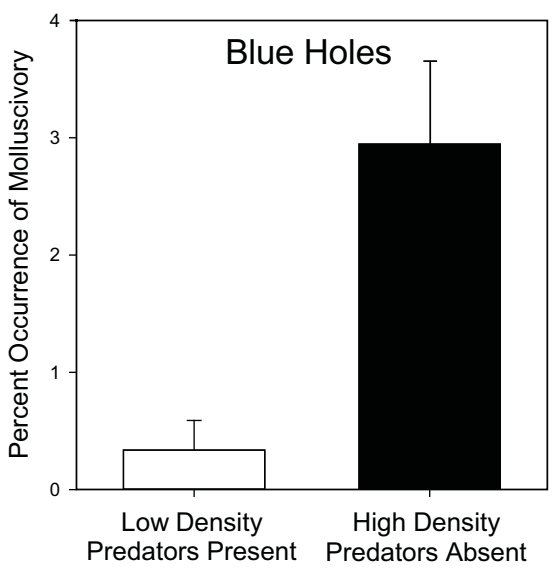

B

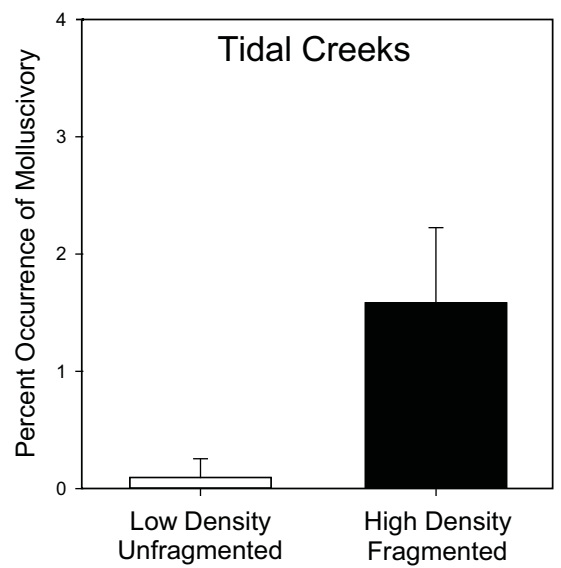

FIGURE 4 | Higher frequency of molluscivory associated with higher densities in Bahamian mosquitofish inhabiting (A) inland blue holes on Andros Island and (B) tidal creeks across six Bahamian islands. Back-transformed means \pm SE depicted.

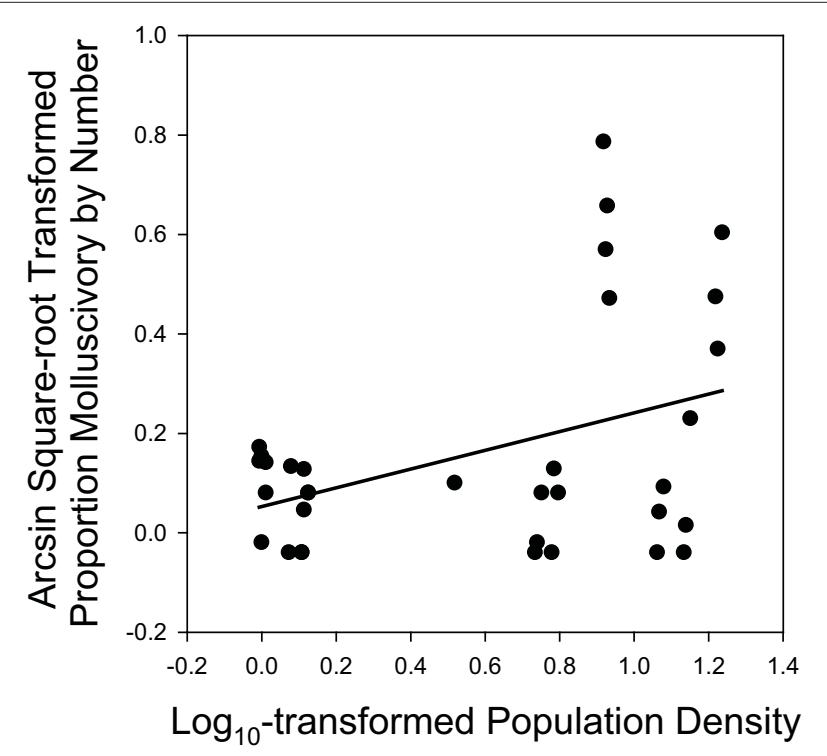

FIGURE 5 | Increased proportion of molluscs in the diet in sites with higher conspecific densities based on stomach-content analyses of male, female, and juvenile Bahamian mosquitofish inhabiting tidal creeks on Abaco Island, The Bahamas (see Supplementary Table 4) based on our general linear model (see text).

$16.9 \%$ (molluscs as a percent of total prey items in the stomach). Consumption of molluscs was positively associated with population density $\left(F_{1,30}=5.58, P=0.0248\right.$; Figure 5), while variation among sex/age classes was not significant $\left(F_{1}, 30\right.$ $=0.82, P=0.45)$.

\section{Experimental Test of Cost of Molluscivory and Compensatory Growth in G. holbrooki}

During the experiment, fish consumed the majority of prey given to them (184 of 192 snails in hard-prey treatment, 178 of 192 snail bodies in soft-prey treatment). For the hard-prey treatment,
TABLE 2 | Results of repeated-measures general linear mixed model examining variation in Gambusia holbrooki growth rate in the feeding experiment.

\begin{tabular}{lccc}
\hline Source & $\boldsymbol{F}$ & $\boldsymbol{d f}$ & $\boldsymbol{P}$ \\
\hline Feeding period & 16.37 & 1.48 & 0.0002 \\
Prey treatment & 0.07 & 1.48 & 0.7964 \\
Standard length & 2.26 & 1.48 & 0.1393 \\
Snail mass & 2.94 & 1.48 & 0.0929 \\
$\begin{array}{l}\text { Prey treatment } \times \\
\text { Feeding period }\end{array}$ & 8.70 & 1.48 & 0.0049 \\
$\begin{array}{l}\text { Snail mass } \times \text { Feeding } \\
\text { period }\end{array}$ & 5.20 & 1.48 & 0.0271 \\
\hline
\end{tabular}

all snail shells were likely swallowed whole, as intact and empty shells of $94 \%$ of the snails consumed by G. holbrooki were found on the bottom of the aquarium (remaining shells were not found), and no case of shell crushing has ever been documented for any Gambusia fish.

In our repeated-measures general linear mixed model, we found significant effects of two key terms on G. holbrooki growth rate: the prey treatment-by-feeding period interaction term and the snail mass-by-feeding period interaction term (Table 2). The clearest result from the experiment indicated that fish in the hard-prey treatment exhibited a reduced growth rate during the snail-feeding period relative to the soft-prey treatment, but elevated growth rate during the flake-feeding period (Figure 6A). This reflects a growth-rate cost of consuming hard-shelled prey, but also the presence of compensatory growth in fish receiving a high-quality diet after a period of consuming costly prey items. The second effect revealed by this experiment indicated that snail mass only influenced $G$. holbrooki growth rate during the snail-feeding period (not the flake-feeding period), with lower growth rates in fish fed larger snails on average- a trend primarily evident in the hard-prey treatment (Figures 6B,C). 


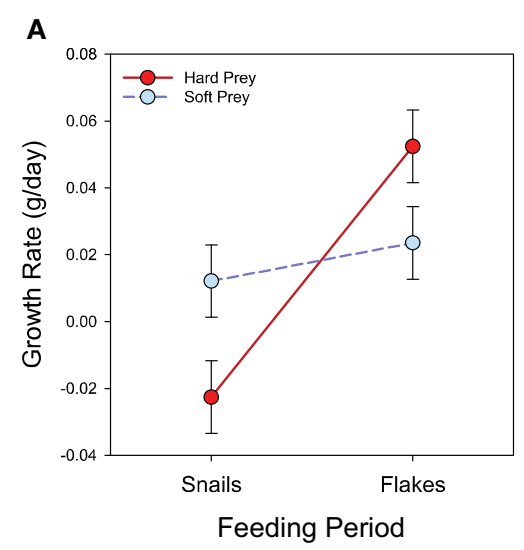

B

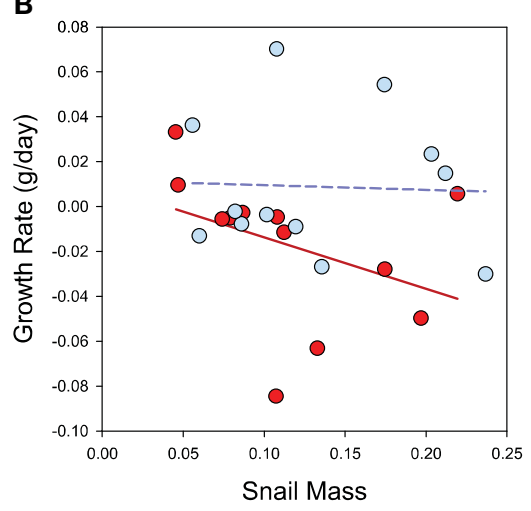

(Snail-feeding Period)

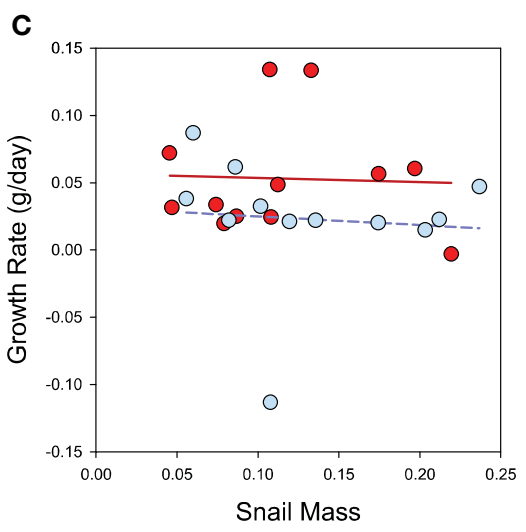

(Flake-feeding Period)

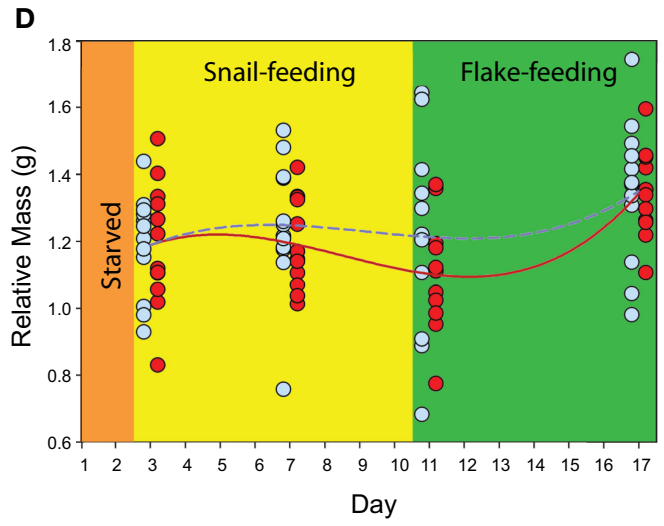

FIGURE 6 | Feeding experiment results in Gambusia holbrooki illustrating (A) differences in growth rate between hard- and soft-prey treatments during both snail-feeding and flake-feeding periods (least-squares means \pm 1 standard error), (B,C) relationship between snail weight fed to fish and growth rate for both hardand soft-prey treatments during (B) the snail-feeding period and (C) the flake-feeding period, and (D) overall pattern of mass change (relative to body length) during the experiment.

Overall, growth trajectories of the two treatments tended to diverge early in the experiment, reaching the maximal difference around the end of the snail-feeding period, but then converged by the end of the experiment due to compensatory growth during the flake-feeding period (Figure 6D). The estimated compensatory index was $93 \%$, indicating a robust recovery of mass loss for fish in the hard-prey treatment via compensatory growth during the 6-day flake-feeding period.

\section{DISCUSSION}

Many animals eat a wide variety of prey, including items that likely elicit energetic, health, or reproductive costs, such as highly toxic or hard-shelled prey. Here we demonstrated that (1) durophagy is widespread in teleost fishes and that the majority of species that consume hard-shelled prey lack any relevant feeding specializations, (2) low levels of durophagy are prevalent throughout the range of $G$. holbrooki even though it results in reduced growth, (3) higher incidence of durophagy occurs under conditions of higher intraspecific competition for resources in Bahamian mosquitofish, and (4) compensatory growth can mitigate growth-related costs of durophagy. Overall, our results suggest that animals consume costly prey at a nonnegligible frequency, increasing their consumption of these prey when high-quality prey become relatively scarce, and cope with the growth-depressing impacts of costly prey by exhibiting compensatory growth that offsets costs if alternative prey can be later acquired.

\section{Costly Prey}

While few would dispute the notion that many animals often consume suboptimal prey, an important question concerns the frequency with which animals consume truly costly prey in nature. To date, we have little relevant data to directly address this question, but much anecdotal evidence. Here we focused on durophagy, which is not only widely thought to entail considerable costs (see Introduction), but we experimentally confirmed a cost in terms of growth rate in the non-specialized fish G. holbrooki after eating molluscs for only 8 days. Our experimental design, which compared consumption of snails with intact shells to the consumption of only the snail bodies, allowed us to explicitly reveal growth-related costs of shell consumption per se, revealing the cost of consuming the hard, indigestible component of hard-shelled prey. Moreover, growth 
costs manifested rapidly even in adults, suggesting growth costs for juveniles or during longer-term durophagy would likely be more severe. In small livebearing fish, like Gambusia spp., gastropod shells can take up a significant portion of the gut, restricting the space available for other food or, in the case of pregnant females, for developing offspring within the body cavity. Therefore, molluscivory might affect growth, reproduction, and survival in Gambusia fishes. Hard-bodied prey are generally swallowed whole in non-specialized taxa, with littleto-no nutrition gained from the dense material. Thus, many, perhaps most, non-specialized animals likely experience a cost in terms of growth or fecundity when consuming hard-shelled prey relative to a soft-prey diet.

\section{Regularity of Consumption of Costly Prey}

Despite the apparent disadvantages, we found that costly-prey consumption appears widespread in nature. A majority of nonspecialized species examined in our literature review exhibited durophagy, consuming $\sim 30-45 \%$ as much hard-shelled prey as specialists based on number, weight, and volume of diet items. Moreover, durophagy occurred throughout much of the native ranges of G. holbrooki, G. hubbsi, G. manni, and G. sp.--small, viviparous taxa that seem particularly vulnerable to durophagy-induced costs. Combined with previous work, this suggests that Gambusia fishes may regularly consume molluscs in the wild, sometimes at moderate to high frequencies [e.g., $G$. affinis: 58\% occurrence (Walters and Legner, 1980), G. nobilis: $29 \%$ occurrence (Hubbs et al., 1978)]. Consumption of costly prey thus does not appear restricted to episodes of severe environmental harshness, but instead occurs, at least at low to moderate levels, throughout the year across many regions.

The apparent trend observed using $\mathrm{x}$-ray methods where female Gambusia fishes often showed a higher frequency of molluscivory than males probably reflects the larger body size of females in these species, and their subsequent consumption of larger molluscs that are more dense and detectable with radiography. Indeed, our direct examination of stomach contents revealed more frequent consumption of smaller molluscs across all age and sex classes, with no differences between the sexes. That said, livebearing females may more regularly consume larger and denser snails than males due to their greater energy requirements - a pattern that could lead to considerable costs, as our experiment showed that consumption of larger snails had more negative consequences for growth. Interestingly, even though stomach-content analyses revealed higher absolute estimates of molluscivory than the x-ray methods, both methodological approaches pointed to the same associations with resource competition (see below). This suggests that $\mathrm{x}$ ray methods underestimate total molluscivory, but provide reliable relative estimates of molluscivory, and reveal cases with strong likelihoods of fitness costs owing to the size and density of detectable shells. To determine the generality of our findings, future work should investigate the frequency of consumption of other types of costly prey, examine other taxa, and experimentally confirm the costliness of consumption of particular prey.

\section{Costly Prey and Optimal Foraging Theory}

According to optimal foraging theory, as high-quality foods become more difficult to acquire, animals should incorporate more suboptimal prey in their diet. Consistent with this prediction, the frequency of durophagy in our focal species appears related to resource competition-Bahamian Gambusia exhibited increased molluscivory in populations with higher density. This pattern was evident across three species spanning six islands inhabiting two different types of ecosystems (blue holes and tidal creeks), regardless of whether we used $\mathrm{x}$ rays to detect molluscivory or stomach contents to quantify relative consumption of molluscs. This suggests that increased competition for food resources in these high-density populations elicits increased utilization of costly prey that provide little benefit relative to starving. While most of the mollusc species observed within Gambusia diets are present within nearly all study sites (RBL pers. obs.), and preliminary examination within a subset of these sites has found no covariation between mollusc abundance and Gambusia population density (RBL unpubl. data), future work should directly examine this topic. In the present study, predation risk may provide an additional contributing factor, as prey could alter activity levels or utilize alternative habitats with varying mollusc abundances in the presence of predators, and thus encounter mollusc prey at different frequencies in high-predation/low-density environments compared to lowpredation/high-density environments. Regardless, swallowing whole snail shells that occupy considerable space in the digestive tract and body cavity, and eventually expelling them whole, poses a range of risks and potential costs with comparatively little energetic gain from the snail body. Thus, molluscivory should presumably be exceedingly rare except in extreme circumstances-but our findings in the literature survey and across the range of four Gambusia species indicate that it is not as rare as one might expect, suggesting an additional mechanism that mitigates its costs may be prevalent.

\section{Costly Prey and Compensatory Growth}

Compensatory growth is widespread across animal taxa (see Box 1 and references therein) and could represent a common means of offsetting growth costs caused by eating costly prey. Compensatory growth has traditionally been viewed as an evolved mechanism that (at least partially) offsets fitness costs imposed by food shortage or a reduced growing season, but perhaps compensatory growth is more profitably viewed as a generalized life-history strategy to buffer adult body size against a wide range of environmental perturbations that could potentially reduce body size. Thus, compensatory growth might not only occur in response to food restriction or time constraints but also to generalized cues of a reduced probability of achieving an optimal body size. This means it might represent an important, previously unrecognized means of counteracting growth-depressing effects of the widespread phenomenon of costly-prey consumption.

The magnitude and rate of compensatory growth that we observed in G. holbrooki suggests this mechanism might greatly reduce, or even eliminate, potential fitness costs in the wild under a range of scenarios of low to moderate consumption 
of costly prey. Whether compensatory growth might vary with age, sex, stage of pregnancy, or duration of durophagy is currently unknown, but previous work has found some of these factors can influence the degree of compensatory growth [e.g., see Wilson and Osbourn (1960)]. Because the adaptive benefit of compensatory growth depends on the likelihood of surviving until high-quality food is re-acquired, this suggests that animals inhabiting environments with especially high mortality rates following costly-prey consumption should exhibit reduced levels of compensatory growth compared to organisms in lowmortality environments. Future work could test this hypothesis using comparative data across populations or species.

While compensatory growth can provide important benefits that mitigate costs of eating certain prey resources, it can also entail costs of its own, explaining why animals don't always exhibit the high growth rates observed during phases of compensatory growth (Arendt, 1997; Mangel and Stamps, 2001; Metcalfe and Monaghan, 2001; Johnsson and Bohlin, 2006; Royle et al., 2006; De Block and Stoks, 2008; Dmitriew, 2011; Hector and Nakagawa, 2012; Kahn et al., 2012). Faster than optimal growth can involve a range of costs, such as reductions in cell functioning efficiency, immune function, resistance to physiological stressors, fecundity, dominance rank, body size, locomotor performance, mating attractiveness, and lifespan. As long as the benefits outweigh the costs, compensatory growth provides an adaptive strategy for contending with costly prey. Considering that many of the purported costs of compensatory growth are delayed until later in life, often after (at least initial) reproduction (Metcalfe and Monaghan, 2001; Yearsley et al., 2004; Stoks et al., 2006; Ab Ghani and Merilä, 2014), combined with the ubiquity of compensatory growth in animals (e.g., Wilson and Osbourn, 1960; Tanner, 1963; Ali et al., 2003; Hector and Nakagawa, 2012), it may be that the fitness benefits indeed typically outweigh the costs in many natural systems. Nevertheless, to better understand the evolution of compensatory growth and its role in coping with the consumption of costly prey, future work should examine the potential costs of compensatory growth and their fitness consequences.

One area that seems to warrant future attention is how costlyprey consumption and compensatory growth might influence reproductive strategies. For instance, whether compensatory growth might often involve reproductive tissue, as opposed to somatic growth, has not yet been explored. Costly-prey consumption might affect reproductive traits such as egg development, yolk content, nutrient transfer to embryos, and embryo abortion. Moreover, while large body size often enhances fitness (Roff, 2002), elevated somatic growth can sometimes have smaller fitness consequences than reproductive traits that directly increase fecundity. Thus, we might expect to find compensatory reproduction following costly-prey consumption in some taxa. That is, if compensatory growth represents a lifehistory adaptation to achieve high fitness in the face of costlyprey consumption through rapid attainment of appropriate body size, then compensatory reproduction might represent an alternative, non-mutually exclusive strategy to maintain high reproductive output, especially later in life when somatic growth has less importance for fitness and future reproductive output is at a premium [essentially a special case of the terminalinvestment hypothesis, (Charlesworth and Leon, 1976; CluttonBrock, 1984)]. Therefore, animals might exhibit compensatory growth of reproductive tissues, such as larger or more numerous eggs or embryos, or invest more in reproductive behaviors, to compensate for lost reproductive output or mating opportunities. Future work should examine how costly-prey consumption might influence reproductive strategies.

\section{CONCLUSION}

Our results, combined with both the established predictive power of optimal foraging theory and the pervasiveness of compensatory growth in animals, point to these two mechanisms as factors of general importance in explaining why animals may regularly include costly prey in their diet. Thus, it appears that a profitable avenue for future investigation would center on optimal foraging and compensatory growth as major explanations for costly-prey consumption in nature.

\section{DATA AVAILABILITY STATEMENT}

The original contributions presented in the study are included in the article/Supplementary Materials, and available from the Dryad Digital Repository: https://doi.org/10.5061/dryad. mkkwh70z4 (Langerhans et al., 2020).

\section{ETHICS STATEMENT}

Animal research was reviewed and approved by the Institutional Animal Care and Use Committee of North Carolina State University (protocol 13-101-O).

\section{AUTHOR CONTRIBUTIONS}

RL conceived and coordinated the study, analyzed the data, and prepared the original manuscript. TG and KS performed the literature survey and laboratory experiment. RR led the field survey of G. holbrooki. RR, MA, and CL assisted with Bahamian mosquitofish components. RL and TG collected molluscivory data using $\mathrm{x}$-rays. MA conducted the stomachcontent analyses of Bahamian mosquitofish. CL made intellectual contributions to the work. All authors contributed significant edits to the manuscript.

\section{FUNDING}

Funding was provided by the National Science Foundation (DEB-0842364) and North Carolina State University.

\section{ACKNOWLEDGMENTS}

We thank J. Warrillow for assistance with digital radiography and live-fish care; R. Martin and S. Diamond for help collecting G. holbrooki for the population survey; S. Giery for help collecting G. sp. for stomach-content analysis; and the Langerhans Lab 
Group for constructive comments on an earlier version of the manuscript. All preserved specimens used in this study were deposited in the Langerhans Laboratory Specimen and Tissue Collection (LLSTC, searchable online: http://gambusia.zo.ncsu. edu/DRILL).

\section{REFERENCES}

Ab Ghani, N. I., and Merilä, J. (2014). Cross-generational costs of compensatory growth in nine-spined sticklebacks. Oikos 123, 1489-1498. doi: 10.1111/oik.01597

Ali, M., Nicieza, A., and Wootton, R. J. (2003). Compensatory growth in fishes: a response to growth depression. Fish Fish. 4, 147-190. doi: 10.1046/j.1467-2979.2003.00120.x

Araujo, M. S., Bolnick, D. I., and Layman, C. A. (2011). The ecological causes of individual specialisation. Ecol. Lett. 14, 948-958. doi: 10.1111/j.1461-0248.2011.01662.x

Araujo, M. S., Langerhans, R. B., Giery, S. T., and Layman, C. A. (2014). Ecosystem fragmentation drives increased diet variation in an endemic livebearing fish of the Bahamas. Ecol. Evol. 4, 3298-3308. doi: 10.1002/ece3.1140

Arendt, J. D. (1997). Adaptive intrinsic growth rates: an integration across taxa. Q. Rev. Biol. 72, 149-177. doi: 10.1086/419764

Bay, E. C., and Anderson, L. D. (1966). Studies with mosquitofish, Gambusia affinis, as a chironomid control. Ann. Entomol. Soc. Am. 59, 150-153. doi: 10.1093/aesa/59.1.150

Beckmann, M. C., Gilliam, J. F., and Langerhans, R. B. (2015). X-ray imaging as a time-saving, non-invasive technique for diet analysis. Fish. Res. 161, 1-7. doi: 10.1016/j.fishres.2014.05.015

Benkman, C. W. (1993). Adaptation to single resources and the evolution of crossbill (Loxia) diversity. Ecol. Monogr. 63, 305-325. doi: 10.2307/2937103

Bernays, E. A., Bright, K. L., Gonzalez, N., and Angel, J. (1994). Dietary mixing in a generalist herbivore: tests of two hypotheses. Ecology 75, 1997-2006. doi: $10.2307 / 1941604$

Björnerås, C., Škerlep, M., Gollnisch, R., Herzog, S. D., Ekelund Ugge, G., Hegg, A., et al. (2020). Inland blue holes of The Bahamas - chemistry and biology in a unique aquatic environment. Fundam. Appl. Limnol. 194, 95-106. doi: $10.1127 /$ fal $/ 2020 / 1330$

Bohman, V. R. (1955). Compensatory growth of beef cattle: the effect of hay maturity. J. Anim. Sci. 14, 249-255. doi: 10.2527/jas1955.141249x

Bolnick, D. I. (2001). Intraspecific competition favours niche width expansion in Drosophila melanogaster. Nature 410, 463-466. doi: 10.1038/35068555

Bolnick, D. I., Svanback, R., Fordyce, J. A., Yang, L. H., Davis, J. M., Hulsey, C. D., et al. (2003). The ecology of individuals: incidence and implications of individual specialization. Am. Nat. 161, 1-28. doi: 10.1086/343878

Brodie, E. D. (1999). Costs of exploiting poisonous prey: evolutionary trade-offs in a predator-prey arms race. Evolution 53, 626-631. doi: 10.1111/j.1558-5646.1999.tb03798.x

Charlesworth, B., and Leon, J. A. (1976). Relation of reproductive effort to age. Am. Nat. 110, 449-459. doi: 10.1086/283079

Chase, J. M., and Leibold, M. (2003). Ecological Niches. Linking Classical and Contemporary Approaches. Chicago, IL: University of Chicago Press.

Clutton-Brock, T. H. (1984). Reproductive effort and terminal investment in iteroparous animals. Am. Nat. 123, 212-229. doi: 10.1086/284198

Coley, P. D., and Barone, J. A. (1996). Herbivory and plant defenses in tropical forests. Annu. Rev. Ecol. Syst. 27, 305-335. doi: 10.1146/annurev.ecolsys.27.1.305

Cortes, E. (1997). A critical review of methods of studying fish feeding based on analysis of stomach contents: application to elasmobranch fishes. Can. J. Fish. Aquat. Sci. 54, 726-738. doi: 10.1139/f96-316

De Block, M., and Stoks, R. (2008). Compensatory growth and oxidative stress in a damselfly. Proc. Roy. Soc. B. 275, 781-785. doi: 10.1098/rspb.2007.1515

Dmitriew, C. M. (2011). The evolution of growth trajectories: what limits growth rate? Biol. Rev. 86, 97-116. doi: 10.1111/j.1469-185X.2010.00136.x

Fairbanks, R. G. (1989). A 17,000-year glacio-eustatic sea level record: influence of glacial melting rates on the younger dryas event and deep-ocean circulation. Nature 342, 637-642. doi: 10.1038/342637a0

Giery, S. T., Layman, C. A., and Langerhans, R. B. (2015). Anthropogenic ecosystem fragmentation drives shared and unique patterns of sexual signal

\section{SUPPLEMENTARY MATERIAL}

The Supplementary Material for this article can be found online at: https://www.frontiersin.org/articles/10.3389/fevo. 2020.603387/full\#supplementary-material

divergence among three species of Bahamian mosquitofish. Evol. App. 8, 679-691. doi: 10.1111/eva.12275

Grubich, J. (2003). Morphological convergence of pharyngeal jaw structure in durophagous perciform fish. Biol. J. Linn. Soc. 80, 147-165. doi: 10.1046/j.1095-8312.2003.00231.x

Hector, K. L., and Nakagawa, S. (2012). Quantitative analysis of compensatory and catch-up growth in diverse taxa. J. Anim. Ecol. 81, 583-593. doi: 10.1111/j.1365-2656.2011.01942.x

Heinen, J. L., Coco, M. W., Marcuard, M. S., White, D. N., Peterson, M. N., Martin, R. A., et al. (2013). Environmental drivers of demographics, habitat use, and behavior during a post-pleistocene radiation of Bahamas mosquitofish (Gambusia hubbsi). Evol. Ecol. 27, 971-991. doi: 10.1007/s10682-012-9627-6

Heinen-Kay, J. L., Noel, H. G., Layman, C. A., and Langerhans, R. B. (2014). Human-caused habitat fragmentation can drive rapid divergence of male genitalia. Evol. Appl. 7, 1252-1267. doi: 10.1111/eva.12223

Heinen-Kay, J. L., Schmidt, D. A., Stafford, A. T., Costa, M. T., Peterson, M. N., Kern, E. M. A., et al. (2016). Predicting multifarious behavioural divergence in the wild. Anim. Behav. 121, 3-10. doi: 10.1016/j.anbehav.2016. 08.016

Hornick, J. L., Van Eenaeme, C., Gerard, O., Dufrasne, I., and Istasse, L. (2000). Mechanisms of reduced and compensatory growth. Domest. Anim. Endocrinol. 19, 121-132. doi: 10.1016/S0739-7240(00)00072-2

Hubbs, C. (1990). Snails as a food source for Gambusia. Tex. J. Sci. 42, 245-256.

Hubbs, C., Lucier, T., Marsh, E., Garrett, G. P., Edwards, R. J., and Milstead, E. (1978). Results of an eradication program on the ecological relationships of fishes in Leon Creek, Texas. Southwest. Nat. 23, 487-496. doi: 10.2307/3670255

Hulsey, C. D., Roberts, R. J., Lin, A. S. P., Guldberg, R., and Streelman, J. T. (2008). Convergence in a mechanically complex phenotype: detecting structural adaptations for crushing in cichlid fish. Evolution 62, 1587-1599. doi: 10.1111/j.1558-5646.2008.00384.x

Johnsson, J. I., and Bohlin, T. (2006). The cost of catching up: increased winter mortality following structural growth compensation in the wild. Proc. Roy. Soc. B 273, 1281-1286. doi: 10.1098/rspb.2005.3437

Kahn, A. T., Livingston, J. D., and Jennions, M. D. (2012). Do females preferentially associate with males given a better start in life? Biol. Lett. 8, 362-364. doi: $10.1098 / \mathrm{rsbl} .2011 .1106$

Langerhans, R. B. (2018). Predictability and parallelism of multitrait adaptation. $J$. Hered. 109, 59-70. doi: 10.1093/jhered/esx043

Langerhans, R. B., Gifford, M. E., and Joseph, E. O. (2007). Ecological speciation in Gambusia fishes. Evolution 61, 2056-2074. doi: 10.1111/j.1558-5646.2007.00171.x

Langerhans, R. B., Goins, T. R., Stemp, K. M., and Riesch, R. (2020). Compensatory growth and costs of molluscivory in Gambusia holbrooki [Dataset]. Dryad. doi: 10.5061/dryad.mkkwh70z4

Langerhans, R. B., and Makowicz, A. M. (2013). Sexual selection paves the road to sexual isolation during ecological speciation. Evol. Ecol. Res. 15, 633-651.

Layman, C. A., Arrington, D. A., Langerhans, R. B., and Silliman, B. R. (2004). Degree of fragmentation affects fish assemblage structure in Andros Island (Bahamas) estuaries. Caribb. J. Sci. 40, 232-244.

Liem, K. F. (1986). The pharyngeal jaw apparatus of the Embiotocidae (Teleostei): a functional and evolutionary perspective. Copeia 1986, 311-323. doi: $10.2307 / 1444992$

Livingston, J. D., Kahn, A. T., and Jennions, M. D. (2014). Sex differences in compensatory and catch-up growth in the mosquitofish Gambusia holbrooki. Evol. Ecol. 28, 687-706. doi: 10.1007/s10682-014-9691-1

Lopez-Peralta, R. H., and Arcila, C. A. T. (2002). Diet composition of fish species from the southern continental shelf of Colombia. NAGA Worldfish Center Quart. 25, 23-29.

MacArthur, R. H., and Pianka, E. R. (1966). On optimal use of a patchy environment. Am. Nat. 100, 603-609. doi: 10.1086/282454

Mangel, M., and Stamps, J. (2001). Trade-offs between growth and mortality and the maintenance of individual variation in growth. Evol. Ecol. Res. 3, 583-593. 
Martin, R. A., McGee, M. D., and Langerhans, R. B. (2015). Predicting ecological and phenotypic differentiation in the wild: a case of piscivorous fish in a fishless environment. Biol. J. Linn. Soc. 114, 588-607. doi: 10.1111/bij.12449

McNaughton, S. J. (1983). Compensatory plant growth as a response to herbivory. Oikos 40, 329-336. doi: 10.2307/3544305

Meffe, G. K., and Snelson, F. F. (1989). "An ecological overview of poeciliid fishes," in Ecology and Evolution of Livebearing Fishes (Poeciliidae), eds G. K. Meffe and F. F. Snelson (Englewood Cliffs: Prentice Hall), 13-31.

Metcalfe, N. B., and Monaghan, P. (2001). Compensation for a bad start: grow now, pay later? Trends Ecol. Evol. 16, 254-260. doi: 10.1016/S0169-5347(01)02124-3

Meyer, A. (1990). Ecological and evolutionary consequences of the trophic polymorphism in Cichlasoma citrinellum (Pisces, Cichlidae). Biol. J. Linn. Soc. 39, 279-299. doi: 10.1111/j.1095-8312.1990.tb00517.x

Morin, P. J. (2011). Community Ecology. Malden, MA: Wiley-Blackwell.

Olsson, J., Quevedo, M., Colson, C., and Svanback, R. (2007). Gut length plasticity in perch: into the bowels of resource polymorphisms. Biol. J. Linn. Soc. 90, 517-523. doi: 10.1111/j.1095-8312.2007.00742.x

Osborne, T. B., and Mendel, L. B. (1916). Acceleration of growth after retardation. Am. J. Physiol. 40, 16-U2. doi: 10.1152/ajplegacy.1916.40.1.16

Pen, L. J., and Potter, I. C. (1991). Reproduction, growth and diet of Gambusia holbrooki (Girard) in a temperate Australian river. Aquat. Conserv. 1, 159-172. doi: $10.1002 /$ aqc. 3270010205

Pfennig, D. W., and Pfennig, K. S. (2012). Evolution's Wedge. Competition and the Origins of Diversity. Berkeley, CA: University of California Press.

Pinkas, L., Oliphant, M. S., and Iverson, I. L. K. (1971). Food habits of albacore bluefin tuna and bonito in California waters. Calif. Dept. Fish Game Bull. 152, 3-105.

Provenza, F. D., Villalba, J. J., Dziba, L. E., Atwood, S. B., and Banner, R. E. (2003). Linking herbivore experience, varied diets, and plant biochemical diversity. Small Ruminant Res. 49, 257-274. doi: 10.1016/S0921-4488(03)00143-3

Pyke, G. H. (1984). Optimal foraging theory: a critical review. Annu. Rev. Ecol. Syst. 15, 523-575. doi: 10.1146/annurev.es.15.110184.002515

Pyke, G. H. (2005). A review of the biology of Gambusia affinis and G. holbrooki. Rev. Fish. Biol. Fish. 15, 339-365. doi: 10.1007/s11160-006-6394-x

Pyke, G. H., Pulliam, H. R., and Charnov, E. L. (1977). Optimal foraging: selective review of theory and tests. Q. Rev. Biol. 52, 137-154. doi: 10.1086/409852

Randall, J. E. (1967). Food habits of reef fishes of the West Indies. Stud. Trop. Oceanogr. 5, 655-847.

Rex, K., Czaczkes, B. I., Michener, R., Kunz, T. H., and Voigt, C. C. (2010). Specialization and omnivory in diverse mammalian assemblages. Ecoscience 17, 37-46. doi: 10.2980/17-1-3294

Riesch, R., Easter, T., Layman, C. A., and Langerhans, R. B. (2015). Rapid human-induced divergence of life-history strategies in Bahamian livebearing fishes (family Poeciliidae). J. Anim. Ecol. 84, 1732-1743. doi: $10.1111 / 1365-2656.12425$

Riesch, R., Martin, R. A., and Langerhans, R. B. (2013). Predation's role in lifehistory evolution of a livebearing fish and a test of the Trexler-DeAngelis model of maternal provisioning. Am. Nat. 181, 78-93. doi: 10.1086/668597

Roff, D. A. (2002). Life History Evolution. Sunderland, MA: Sinauer Associates Inc.

Royle, N. J., Lindstrom, J., and Metcalfe, N. B. (2006). Effect of growth compensation on subsequent physical fitness in green swordtails Xiphophorus helleri. Biol. Lett. 2, 39-42. doi: 10.1098/rsbl.2005.0414

Ryan, W. J. (1990). Compensatory growth in cattle and sheep. Nutrition Abs. Rev. B 60, 653-664

Savitzky, A. H. (1983). Coadapted character complexes among snakes: fossoriality, piscivory, and durophagy. Am. Zool. 23, 397-409. doi: 10.1093/icb/23.2.397

Schluter, D. (2000). The Ecology of Adaptive Radiation. Oxford: Oxford University Press.

Schoener, T. W. (1971). Theory of feeding strategies. Annu. Rev. Ecol. Syst. 2, 369-404. doi: 10.1146/annurev.es.02.110171.002101

Simpson, S. J., Sibly, R. M., Lee, K. P., Behmer, S. T., and Raubenheimer, D. (2004). Optimal foraging when regulating intake of multiple nutrients. Anim. Behav. 68, 1299-1311. doi: 10.1016/j.anbehav.2004.03.003

Smith, T. B., and Skúlason, S. (1996). Evolutionary significance of resource polymorphisms in fishes, amphibians, and birds. Annu. Rev. Ecol. Syst. 27, 111-133. doi: 10.1146/annurev.ecolsys.27.1.111

Stephens, D. W., and Krebs, J. R. (1986). Foraging Theory. Princeton, NJ: Princeton University Press.
Stoks, R., De Block, M., and McPeek, M. A. (2006). Physiological costs of compensatory growth in a damselfly. Ecology 87, 1566-1574. doi: 10.1890/0012-9658(2006)87[1566:PCOCGI]2.0.CO;2

Svanbäck, R., and Bolnick, D. I. (2007). Intraspecific competition drives increased resource use diversity within a natural population. Proc. Roy. Soc. B 274, 839-844. doi: 10.1098/rspb.2006.0198

Svanbäck, R., and Persson, L. (2004). Individual diet specialization, niche width and population dynamics: implications for trophic polymorphisms. J. Anim. Ecol. 73, 973-982. doi: 10.1111/j.0021-8790.2004.00868.x

Swanson, B. O., Gibb, A. C., Marks, J. C., and Hendrickson, D. A. (2003). Trophic polymorphism and behavioral differences decrease intraspecific competition in a cichlid, Herichthys minckleyi. Ecology 84, 1441-1446. doi: 10.1890/02-0353

Tanner, J. M. (1963). Regulation of growth size in mammals. Nature 199, 845-850. doi: $10.1038 / 199845 \mathrm{a} 0$

Tilman, D. (1982). Resource Competition and Community Structure. Princeton, NJ: Princeton University Press. doi: 10.1515/9780691209654

Valentine-Rose, L., Cherry, J. A., Culp, J. J., Perez, K. E., Pollock, J. B., Arrington, D. A., et al. (2007a). Floral and faunal differences between fragmented and unfragmented Bahamian tidal creeks. Wetlands 27, 702-718. doi: 10.1672/0277-5212(2007)27[702:FAFDBF]2.0.CO;2

Valentine-Rose, L., and Layman, C. A. (2011). Response of fish assemblage structure and function following restoration of two small Bahamian tidal creeks. Restor. Ecol. 19, 205-215. doi: 10.1111/j.1526-100X.2009.00553.x

Valentine-Rose, L., Layman, C. A., Arrington, D. A., and Rypel, A. L. (2007b). Habitat fragmentation decreases fish secondary production in Bahamian tidal creeks. Bull. Mar. Sci. 80, 863-877.

Valentine-Rose, L., Rypel, A. L., and Layman, C. A. (2011). Community secondary production as a measure of ecosystem function: a case study with aquatic ecosystem fragmentation. Bull. Mar. Sci. 87, 913-937. doi: $10.5343 /$ bms.2010.1043

Voigt, C. C., Capps, K. A., Dechmann, D. K. N., Michener, R. H., and Kunz, T. H. (2008). Nutrition or detoxification: why bats visit mineral licks of the Amazonian rainforest. PLoS ONE 3:e2011. doi: 10.1371/journal.pone.0002011

Wainwright, P. C. (1988). Morphology and ecology: functional basis of feeding constraints in Caribbean labrid fishes. Ecology 69, 635-645. doi: $10.2307 / 1941012$

Wainwright, P. C. (2006). "Functional morphology of the pharyngeal jaw apparatus," in Biomechanics of Fishes, eds R. Shadwick and G. V. Lauder (San Diego, CA: Academic Press), 77-101. doi: 10.1016/S1546-5098(05) 23003-0

Walters, L. L., and Legner, E. F. (1980). Impact of the desert pupfish, Cyprinodon macularius, and Gambusia affinis affinis on fauna in pond ecosystems. Hilgardia 48, 1-18. doi: 10.3733/hilg.v48n03p018

Westoby, M. (1978). What are biological bases of varied diets? Am. Nat. 112, 627-631. doi: 10.1086/283303

Wilson, P. N., and Osbourn, D. F. (1960). Compensatory growth after undernutrition in mammals and birds. Biol. Rev. Camb. Philos. Soc. 35, 324-363. doi: 10.1111/j.1469-185X.1960.tb01327.x

Winemiller, K. O., and Ponwith, B. J. (1998). Comparative ecology of eleotrid fishes in central American coastal streams. Environ. Biol. Fish. 53, 373-384. doi: 10.1023/A:1007422821071

Won, E. T., and Borski, R. J. (2013). Endocrine regulation of compensatory growth in fish. Front. Endocrinol. 4:74. doi: 10.3389/fendo.2013.00074

Yearsley, J. M., Kyriazakis, I., and Gordon, I. J. (2004). Delayed costs of growth and compensatory growth rates. Funct. Ecol. 18, 563-570. doi: $10.1111 / j .0269-8463.2004 .00879 . x$

Conflict of Interest: The authors declare that the research was conducted in the absence of any commercial or financial relationships that could be construed as a potential conflict of interest.

Copyright $\odot 2021$ Langerhans, Goins, Stemp, Riesch, Araújo and Layman. This is an open-access article distributed under the terms of the Creative Commons Attribution License (CC BY). The use, distribution or reproduction in other forums is permitted, provided the original author(s) and the copyright owner(s) are credited and that the original publication in this journal is cited, in accordance with accepted academic practice. No use, distribution or reproduction is permitted which does not comply with these terms. 